\title{
Effect of GnRH treatment during the anovulatory season on multiple ovulation rate and on follicular development during the ensuing pregnancy in mares
}

\author{
O. J. Ginther and D. R. Bergfelt \\ University of Wisconsin-Madison, Department of Veterinary Science, 1655 Linden Drive, Madison, \\ Wisconsin 53706, USA
}

\begin{abstract}
Summary. Seasonally anovulatory mares were injected, i.m., twice daily with a GnRH analogue (GnRH-A), and hCG was given when the largest follicle reached $35 \mathrm{~mm}$ in diameter. In Exp. 1, treatment was initiated on 23 December when the largest follicle per mare was $\leq 17 \mathrm{~mm}$. An ovulatory response (ovulation within 21 days) occurred in 17 of $30(57 \%)$ GnRH-A-treated mares on a mean of 15.8 days. The shortest interval to ovulation in control mares $(\mathrm{N}=10)$ was 57 days. The diameter of the largest follicle first increased significantly 6 days after start of treatment. In Exp. 2, treatment was begun on 15 January and mares were categorized according to the largest follicle at start of treatment. The proportion of mares ovulating within 21 days increased significantly according to initial diameter of largest follicle ( $\leq 15 \mathrm{~mm}, 9 / 25$ mares ovulated; 15-19 mm, 13/21; 20-24 mm, 20/24; $\geq 25 \mathrm{~mm}, 3 / 3$ ). The multiple ovulation rate was greater $(P<0.01)$ for treated mares $(27 / 86$ mares had multiple ovulations) than for control mares $(2 / 35)$. Treated mares in which the largest follicle at start of treatment was $\geq 25 \mathrm{~mm}$ had a higher $(P<0.01)$ multiple ovulation rate $(9 / 14)$ than did mares in which the largest follicle was $<25 \mathrm{~mm}(18 / 72)$. The pregnancy rate for single ovulators was not different between control mares (26/30 pregnant mares) and treated mares $(43 / 54)$. There was a significant interaction for diameter of largest follicle during pregnancy between day and group (control group and 3 treated groups in which the largest follicle on first day of treatment was $<15,15-19$ or 20-24 mm). On all days from Days 17 to 38 , the largest follicle was larger $(P<0.05)$ in the control group (largest mean, $27.9 \mathrm{~mm}$ ) than in the groups first treated when the largest follicle was $<15 \mathrm{~mm}$ (largest mean, $15.3 \mathrm{~mm}$ ), $15-19 \mathrm{~mm}$ (largest mean, $17.9 \mathrm{~mm}$ ), or $20-24 \mathrm{~mm}$ (largest mean $20 \cdot 2 \mathrm{~mm}$ ).
\end{abstract}

Keywords: GnRH; anovulatory season; ovulation; follicles; horse

\section{Introduction}

A single injection of gonadotrophin releasing hormone $(\mathrm{GnRH})$ in seasonally anovulatory and ovulatory mares causes a transient increase in circulating concentrations of luteinizing hormone (LH; Ginther \& Wentworth, 1974); constant infusion results in continuing LH release (Garcia \& Ginther, 1975). Follicle-stimulating hormone (FSH) also responds to exogenous GnRH; a single injection to seasonally anovulatory mares caused an increase comparable to peak levels during the oestrous cycle (Evans \& Irvine, 1976). Using a complex GnRH protocol consisting of 3 courses (repeated injections) at 10-day intervals plus administration of progesterone, Evans \& Irvine (1977) induced ovulation in 5 of 5 mares towards the end of the anovulatory season. Repeated or prolonged administration of GnRH or GnRH analogues can induce ovulation in mares during the 
anovulatory season (Evans \& Irvine, 1979; Johnson, 1986, 1987; Allen et al., 1987; Fitzgerald et al., 1987; Hyland et al., 1987; Palmer \& Quellier, 1988). In most of these studies, the circulating concentrations of LH and FSH in response to the various regimens of exogenous GnRH were determined, and the relationships among endogenous GnRH, FSH and LH during the anovulatory season have been reviewed (Sharp, 1988). Limited information is available, however, on the effect of follicular status in the anovulatory season at the time of $\mathrm{GnRH}$ treatment on the ovulatory response. In addition, only Johnson (1987) concluded that GnRH administration during the anovulatory season resulted in an increase in the rate of multiple ovulations. Although high pregnancy rates have been reported, there apparently has been no study on the effect of inducing ovulation during the anovulatory season on follicular development during the ensuing pregnancy.

In the present experiments, a GnRH analogue (GnRH-A) was given to mares during the anovulatory season. One objective was to determine the role of follicular status (diameter of largest follicle) at the start of GnRH-A treatment on ovarian response. Additional objectives were to determine the effect of treatment on the incidence of multiple ovulations and on follicular development during early pregnancy.

\section{Materials and Methods}

Animals and general methods. The animals were riding-type horse mares 4-20 years of age and weighed $400-500 \mathrm{~kg}$. The mares were purchased at slaughterhouse auctions and breed was not known. However, the mares appeared to be primarily of Quarter Horse and Appaloosa breeding based on size, conformation, and colour patterns. All mares were non-lactating and in good body condition. For all experiments, the mares were assumed to be seasonally anovulatory on the basis of failure to detect a corpus luteum ultrasonically for several examinations during 10 days preceding an experiment. Mares were not used if they had apparent ovarian or uterine abnormalities based on transrectal ultrasonic inspection.

The ultrasonic examinations of the ovaries and uterus were done as described by Ginther (1986) with a real-time, linear-array scanner equipped with a $5 \mathrm{MHz}$ intrarectal transducer. The ultrasonic scanner was used to measure follicle diameter, determine time of mating, determine day of ovulation, and diagnose pregnancy. The largest follicle on each ovary was measured at 3-day intervals (Exp. 1) or at 3-6-day intervals (Exps 2 and 3) from the beginning of an experiment until a follicle $\geq 25 \mathrm{~mm}$ in diameter was detected; thereafter, follicles were measured daily until ovulation occurred. Most mares were mated when the largest follicle reached $30 \mathrm{~mm}$ and every other day thereafter until ovulation. After ovulation (Day 0), the follicles of mated mares (Exps 1 and 2) were measured every 3 days beginning on Days, 1, 2 or 3, and continuing until diagnosed non-pregnant or, if pregnant, until Days 37,38 or 39 . Pregnancy was diagnosed on Day 11 and confirmed on Days 12-15.

The GnRH-A was obtained as a peptide and had the following altered amino-acid composition: (Des-Gly ${ }^{10}$ ) $\mathrm{D}-$ Ala $^{6}$, Pro ${ }^{9}$-ethylamide-LHRH (Carlsberg Biotechnology Ltd, Copenhagen, Denmark). Before each experiment, GnRH-A was dissolved in $0.154 \mathrm{M}-\mathrm{NaCl}(50 \mu \mathrm{g} / \mathrm{ml})$. Vials of the dissolved $\mathrm{GnRH}$-A were frozen until the day of treatment. The GnRH-A was injected, intramuscularly, every $12 \mathrm{~h}$ at a dose of 100,200 or $400 \mu \mathrm{g}$. Dose was based on a preliminary trial in which twice-daily injections of $200 \mu \mathrm{g}$ appeared to cause follicular stimulation in seasonally anovulatory mares. The GnRH-A was given for the number of days indicated for each experiment or until the occurrence of ovulation. However, if a second follicle $\geq 25 \mathrm{~mm}$ in diameter was present on the day of ovulation, the treatments continued until the second follicle ovulated or regressed to $<25 \mathrm{~mm}$. An intramuscular injection of hCG (2000 i.u.) was given to all mares, including controls, when the largest follicle was $\geq 35 \mathrm{~mm}$ and was repeated at 2 -day intervals until ovulation occurred. No attempt was made to determine the efficacy of hCG for inducing ovulation or multiple ovulation when given in conjunction with the GnRH-A regimen.

Experiment 1. From a population of 136 mares, 40 were randomized into a $\mathrm{GnRH}$-A treated group (dose, $200 \mu \mathrm{g}$; $\mathrm{N}=30$ ) and a control group $(\mathrm{N}=10)$. Treatment of mares and measurement of follicles were begun on 23 December. The diameter of the largest follicle before the experiment ranged from 5 to $17 \mathrm{~mm}$. The GnRH-A was given until ovulation occurred or for 21 days if ovulation did not occur. Mares were kept in natural daylength.

Experiment 2. The remaining 96 mares of the population were randomized into $3 \mathrm{GnRH}-\mathrm{A}$ treated groups (100. 200 or $400 \mu \mathrm{g} \mathrm{GnRH-A}$ ) and a control group ( $\mathrm{N}=24 /$ group). The experiment was begun on 15 January. Treatments were discontinued when ovulation occurred or at 12 days after the first injection if the follicles did not appear to be responding (largest follicle $<25 \mathrm{~mm}$ ). If the largest follicle was $\geq 25 \mathrm{~mm}$ in diameter at 12 days, the injections were continued until ovulation occurred or for 15 additional days. Mares were kept in natural daylength.

Experiment 3. Mares were randomized into the same 4 groups described for Exp. 2 ( $\mathrm{N}=10 /$ group). The mares were under a fixed 15-h light programme that began on 23 December. Treatments were begun on 19 February. The largest follicle was $\geq 20 \mathrm{~mm}$ on the first day of treatment in $55 \%$ of the mares and it cannot be stated unequivocally 
that the mares were seasonally anovulatory. The objectives were to obtain additional data on the effect of GnRH-A on the incidence of multiple ovulations and establishment of pregnancy. The GnRH-A was given as described for Exp. 2 .

Data processing. When the effect of dose of GnRH-A $(100,200 \mathrm{or} 400 \mu \mathrm{g})$ was not significant for an end point, the results for the three doses were combined and compared to those for controls. Results were categorized according to diameter of the largest follicle on the first day of treatment. The preplanned diameter categories were $<15,15-19$, 20-24 and $\geq 25 \mathrm{~mm}$. In Exp. 1, the largest follicle at the start of the experiment was $<15 \mathrm{~mm}$ in all mares, except 2 in which the diameter was $17 \mathrm{~mm}$; therefore, for this experiment the data were not categorized. In some mares in Exp. 2, the largest follicle at the start of treatment was $\geq 25 \mathrm{~mm}$, and in this group of mares the interval from start of treatment to ovulation was not significantly reduced by GnRH-A. Therefore, control mares with the 3 smallest follicle categories $(<15,15-19,20-24 \mathrm{~mm})$ in Exp. 2 and all control mares in Exp. 1 were used to define a positive ovulatory response to treatment. The shortest interval to ovulation in control mares was $2 \mathbf{l}$ days, and a positive ovulatory response in the treated mares was defined as an ovulation occurring within 21 days.

In Exp. 1, diameter of the largest follicle for 21 days after start of treatment was analysed by a day-by-group analysis of variance for sequential data. The groups were controls, treated but negative ovulatory response, and treated and a positive ovulatory response. If a significant day-by-group interaction occurred, a multiple range test was used to locate differences amongst groups within days. Using combined data from Exps 1 and 2, the diameter of the largest follicle during Days 2 to 38 ( \pm 1 day) in pregnant mares was compared among the control group and the 3 treated groups in which the diameter of largest follicle on first day of treatment was $<15,15-19$ or $20-24 \mathrm{~mm}$. The type of analysis was the same as for follicle changes before ovulation in Exp. 1.

The frequencies of an ovulatory response within 21 days in Exp. 2 were examined by $\chi^{2}$ analyses. Comparisons were made among the 4 follicle categories within control and treated mares, among doses within each follicle category, and between treated and control mares within each follicle category. To obtain adequate numbers for studying the effect of GnRH-A on multiple-ovulation rate, data were combined for the 3 experiments. In addition, no differences were found among the 3 smallest follicle categories and the 3 categories were combined, resulting in two categories for diameter of the largest follicle at start of treatment: $<25 \mathrm{~mm}$ and $\geq 25 \mathrm{~mm}$. Data were combined for all experiments to study the effect of GnRH-A treatment on pregnancy rates. Pregnancy rates for single ovulators were examined among control and treated groups by $\chi^{2}$ analyses.

\section{Results}

\section{Experiment 1}

Ovulation occurred by 21 days in 17 of $30(57 \%)$ GnRH-A-treated mares (Fig. 1). The mean interval from 23 December to ovulation in the control group was $111 \pm 11$ days and the shortest interval was 57 days. The interaction of day and group (controls, treated-ovulation and treated-no ovulation) for diameter of largest follicle during the 21 days after onset of treatment was significant (Fig. 1). The diameter first increased significantly in the two treated groups 6 days after the start of treatment.

\section{Experiment 2}

The proportion of mares ovulating in 21 days was different among categories for initial diameter of largest follicle within control mares $(P<0.01)$ and within treated mares $(P<0.005$; Fig. 2): the incidence of ovulation increased as the categories for follicular diameter increased. The proportion of mares ovulating was greater for the treated group than for the control group within initial diameter categories of $<15 \mathrm{~mm}(P<0.1), 15-19 \mathrm{~mm}(P<0.005)$ and $20-24 \mathrm{~mm}$ $(P<0.005)$.

\section{Diameter of largest follicle during pregnancy (Exps 1 and 2)}

There was a main effect of day $(P<0.0001)$ and group (control group and 3 treated groups in which the largest follicle was $<15 \mathrm{~mm}, 15-19 \mathrm{~mm}$, or $20-24 \mathrm{~mm}$ at the start of the experiment; $P<0.0001)$ and a day-by-group interaction $(P<0.0001 ;$ Fig. 3$)$. There were significant differences among groups within days for each of Days 11-38; diameter was greater for the control group on all days. Within the treated groups, diameter was significantly smaller for the $<15 \mathrm{~mm}$ group than for one or both of the other groups on Days 11-26. There was no significant difference between the 


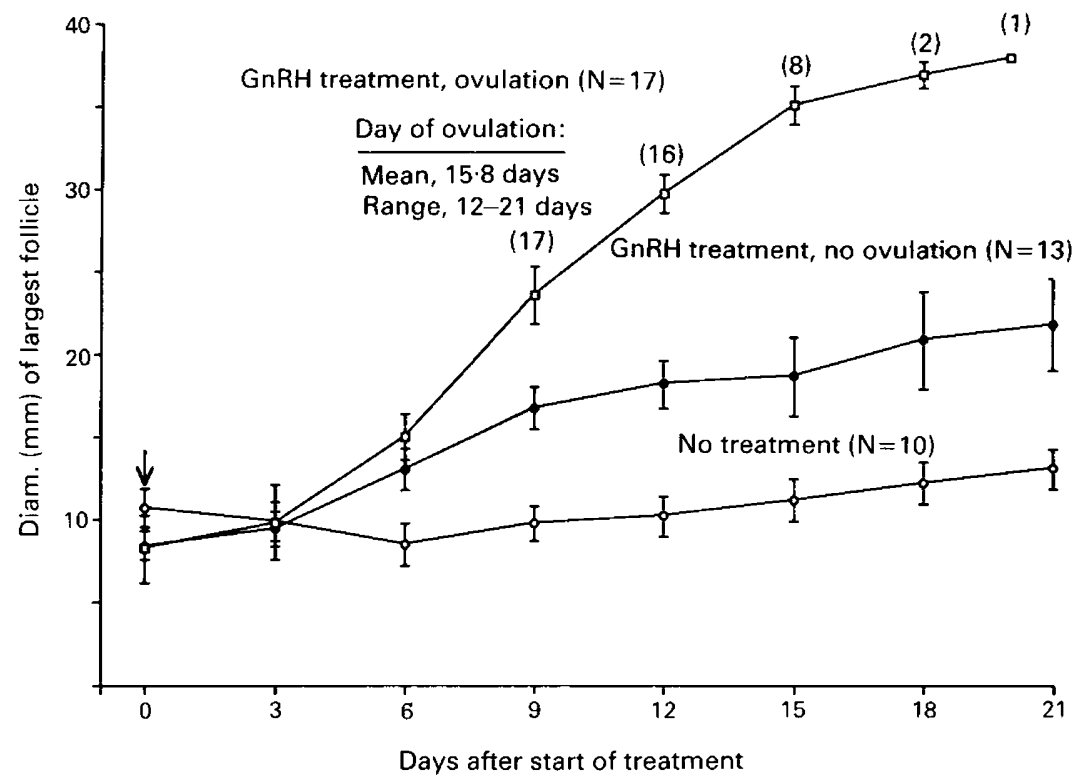

Fig. 1. Mean ( \pm s.e.m. for no. of observations in parentheses) diameters of largest follicle for various days after start of treatment (23 December) in Exp. 1. Numbers of mares decrease because mares were removed when ovulation occurred. The interaction of day and group was significant. The first day of a significant difference between untreated and treated mares was Day 6.

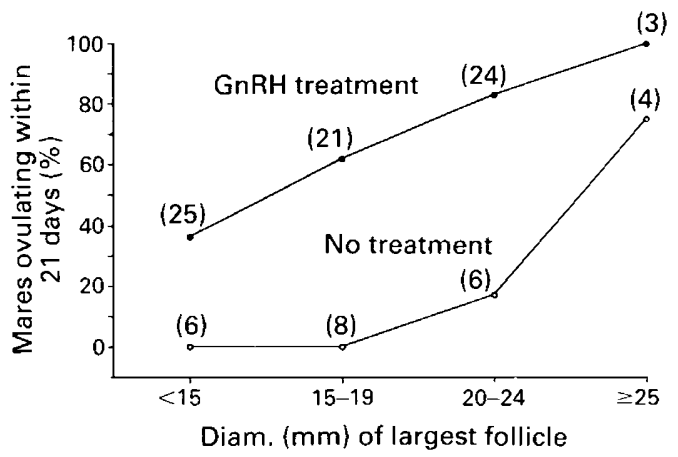

Fig. 2. Influence of diameter of largest follicle at first day of treatment on percentage of mares ovulating within 21 days in Exp. 2. Number in parentheses is total number of mares (e.g. in the GnRH treatment group in which the largest follicle on first day of treatment was $<15 \mathrm{~mm}$, $36 \%$ of 25 mares ovulated). Difference between treated and untreated mares for each diameter category: $<15 \mathrm{~mm}(P<0.1), 11-19 \mathrm{~mm}(P<0.005), 20-24 \mathrm{~mm}(P<0.005), \geq 25 \mathrm{~mm}$ (NS). Difference among untreated groups $(P<0.01)$. Difference among treated groups $(P<0.005)$.

11-19 $\mathrm{mm}$ and 20-24 $\mathrm{mm}$ groups within any day. Two mares had a follicle $\geq 25 \mathrm{~mm}$ on the first day of treatment, and follicular development during early pregnancy seemed similar to that of control mares.

\section{Pregnancy rates and multiple ovulation rates (Exps 1-3)}

The multiple ovulation rate was not altered significantly by dose of GnRH-A (Table 1). Combined for the 3 doses, mares in which the diameter of largest follicle was $\geq 25$ on the first day 


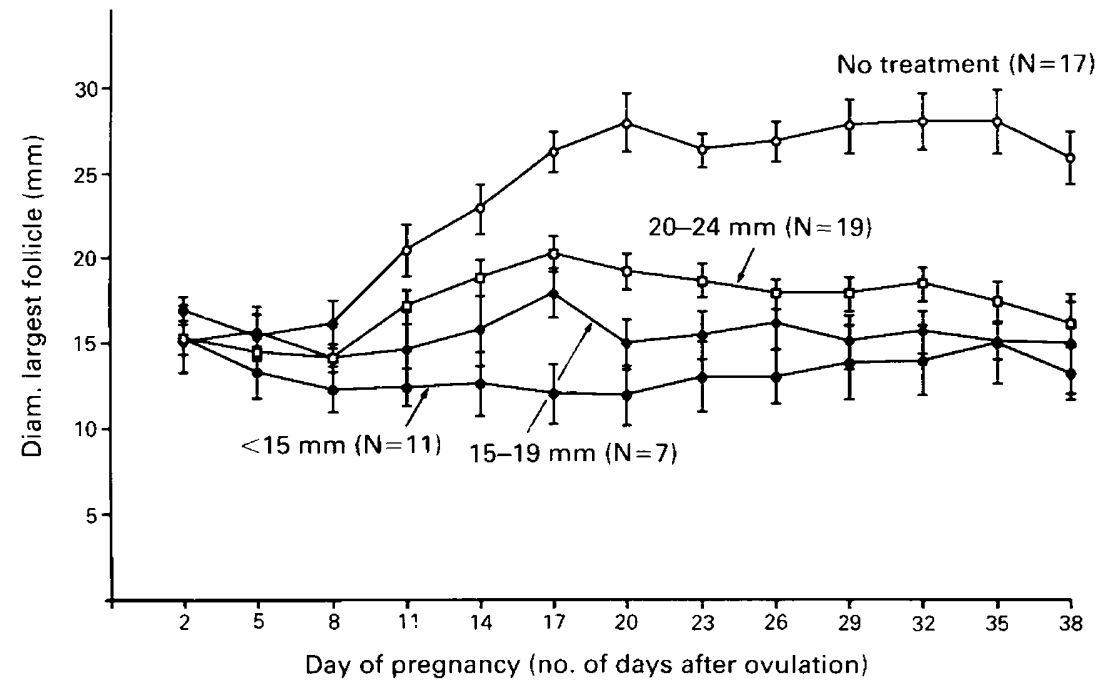

Fig. 3. Mean ( \pm s.e.m.) diameter of largest follicle during early pregnancy in control mares and in treated mares in which the largest follicle on first day of treatment was $<15,15-19$ or 20-24 mm (Exps 1 and 2). Day by group interaction $(P<0 \cdot 0001)$. The mean in the control group was greater $(P<0.05)$ than in each of the 3 treated groups on each of Days 17-38. The mean for the $<15 \mathrm{~mm}$ group was smaller $(P<0.05)$ than that for the $15-19 \mathrm{~mm}$ group on Day 17 and smaller than for the 20-24 mm group on Days 11-26.

of treatment had a higher $(P<0.01)$ multiple ovulation rate than mares in which the diameter was $<25 \mathrm{~mm}$. The multiple ovulation rate was higher $(P<0.01)$ for treated mares (combined for all doses and diameter categories) than for controls. Induction of ovulation did not result in an altered pregnancy rate in single ovulating mares (Table 2).

Table 1. Effect of GnRH-A treatment on percentage of ovulatory mares with multiple ovulations (combined data for Exps 1, 2, and 3)

\begin{tabular}{|c|c|c|c|c|}
\hline \multirow{3}{*}{$\frac{\text { Group }}{\text { Control }}$} & \multicolumn{3}{|c|}{$\begin{array}{l}\text { Diameter largest follicle } \\
\text { on first day of treatment }\end{array}$} & \multirow[b]{2}{*}{ Total } \\
\hline & $<25 \mathrm{~mm}$ & \multicolumn{2}{|c|}{$\geq 25 \mathrm{~mm}$} & \\
\hline & $1 / 29 \quad(3 \%)$ & $1 / 6$ & $(17 \%)$ & $2 / 35 \quad(6 \%)$ \\
\hline $\begin{array}{c}\text { GnRH-A } \mathrm{A}_{+}^{+} \\
100 \mu \mathrm{g} \\
200 \mu \mathrm{g} \\
400 \mu \mathrm{g}\end{array}$ & $\begin{array}{r}2 / 17(12 \%) \\
10 / 35(29 \%) \\
6 / 20(30 \%)\end{array}$ & $\begin{array}{l}3 / 4 \\
2 / 3 \\
4 / 7\end{array}$ & $\begin{array}{l}(75 \%) \\
(67 \%) \\
(57 \%)\end{array}$ & $\begin{aligned} 5 / 21 & (24 \%) \\
12 / 38 & (32 \%) \\
10 / 27 & (37 \%)\end{aligned}$ \\
\hline Total & $18 / 72(25 \%)$ & $9 / 14$ & $(64 \%)$ & $27 / 86^{*}(31 \%)$ \\
\hline
\end{tabular}

$* P<0.01$ compared with control.

$\dagger P<0.01$ compared with follicles $<25 \mathrm{~mm}$.

¥Effect of dose not significant.

\section{Discussion}

The shortest interval from start of an experiment to ovulation in the control mares of Exps 1 and 2, categorized according to initial diameter of largest follicle, was 54 days $(<15 \mathrm{~mm}), 41$ days 
Table 2. Effect of induction of a single ovulation with GnRH-A on number of non-pregnant and pregnant mares

\begin{tabular}{cccccc}
\hline & \multicolumn{2}{c}{ Control } & & GnRH-A treatment \\
\cline { 2 - 3 } \cline { 5 - 6 } Experiment & $\begin{array}{c}\text { Not } \\
\text { pregnant }\end{array}$ & Pregnant & & $\begin{array}{c}\text { Not } \\
\text { pregnant }\end{array}$ & Pregnant \\
\hline 1 & 2 & 7 & & 1 & 5 \\
2 & 1 & 13 & & 8 & 23 \\
3 & 1 & 6 & & 2 & 15 \\
Total & 4 & $26(87 \%)$ & & 11 & $43(80 \%)$ \\
\hline
\end{tabular}

(15-19 mm), 21 days $(20-24 \mathrm{~mm})$ and 3 day $(\geq 25 \mathrm{~mm})$. The second shortest interval in the $<15$, 15-19 and 20-24 mm categories was 39 days. These results confirmed that most, if not all, of the GnRH-A-treated mares, except for the mares with follicles $\geq 25 \mathrm{~mm}$ (Exp. 2), were in a seasonally anovulatory status at the beginning of the treatment regimen. The $\geq 25 \mathrm{~mm}$-group could have included mares that had previously ovulated. The results confirmed that ovulation can be induced by administration of GnRH or its analogues in seasonally anovulatory mares. Reported successful inductions with natural GnRH have involved repeated injections per day at 10-day intervals (Evans \& Irvine, 1977), pulsatile delivery with infusion pumps (Johnson, 1986, 1987; Palmer \& Quellier, 1988), and constant delivery with osmotic minipumps (Hyland et al., 1987; Palmer \& Quellier, 1988); for analogues, the successful delivery systems have included slow-release implants (Allen et al., 1987) and an injection every $12 \mathrm{~h}$ (Fitzgerald et al., 1987), as was done in the present studies. Clearly, mares will respond to widely diverse methods of $\mathrm{GnRH}$ administration, but no attempts were made in this or previous experiments to compare the efficiency of the many forms of delivery and dose regimens or the efficacy of hCG when given after $\mathrm{GnRH}$-induced follicular stimulation.

Diameter of the largest follicle in an individual mare during the anovulatory season is an indicator of seasonal status; increasingly larger follicles develop gradually over a prolonged time span (e.g. 2 months) before the first ovulation of the ovulatory season (Ginther, 1979). On this basis, mares with the smaller follicles at the start of treatment lagged behind mares with larger follicles in the extent of response to positive seasonal influence (increasing daylength). Results of the present studies demonstrated that the follicular status of the mare at the start of treatment can affect the outcome. Mares with small follicles were less likely to show an ovulatory response. The likelihood of response increased as the initial diameter of follicles increased until the follicles were initially so large ( $\geq 25 \mathrm{~mm}$ ) that the response to GnRH-A was not different from what occurred in controls. These results confirm the conclusion of Hyland et al. (1987) that mares in 'shallow anoestrus' are more likely to respond than are mares in 'deep anoestrus'. Some of the mares that did not respond by ovulating within 21 days did undergo an increase in follicular diameter (Fig. 1). No follicular response was apparent in 3 of 13 mares that did not have an ovulatory response in Exp. 1. In the remaining 10 mares, the largest follicle at 21 days (end of treatment) was larger than in any of the controls; the large follicle at 21 days grew to preovulatory size and then regressed (4 mares) or became haemorrhagic ( 2 mares) or regressed without reaching preovulatory size (4 mares). The studies were not designed, however, to determine critically the subsequent ovarian outcome for mares that did not fully respond to GnRH-A treatment by ovulating. Information was available from Exp. 1 on 5 treated mares with an ovulatory response that did not become pregnant. One mare had an interovulatory interval of normal length and 4 became anovulatory. Apparently, despite the induction of ovulation, mares remained under seasonal control. This result is consistent with that of Johnson (1986) who found that 4 mares treated with GnRH when the largest follicle was $\leq 15 \mathrm{~mm}$ ovulated an average of 52 days after the induced ovulation.

Follicular development was reduced during pregnancy in mares in which ovulation was induced by the GnRH-hCG regimen. Data from Exps 1 and 2 were combined in this analysis to obtain 
adequate numbers for the various size categories. In this regard, mares for the two experiments were randomized from the same pool. In addition, significant differences were obtained between the control group and the $<15 \mathrm{~mm}$ treated group within Exp. 1 and between the control and the $15-19 \mathrm{~mm}$ and $20-24 \mathrm{~mm}$ treated groups within Exp. 2. The continuing effects of season probably account for the reduced follicular development during early pregnancy. The mares with the smallest follicles $(<15 \mathrm{~mm})$ at start of treatment showed the most exaggerated lack of follicular development in early pregnancy. At the other extreme, 2 mares with the largest follicles ( $\geq 25 \mathrm{~mm}$ ) at start of treatment had follicles in early pregnancy that were similar in diameter to those of control mares.

The results clearly show that the oocytes resulting from induced ovulation during the anovulatory season are fully capable of fertilization, in agreement with the reports of Allen $e t$ al. (1987) and Hyland et al. (1987). The pregnancy rate for single ovulators in the present experiments was high for control $(87 \%)$ and treated $(80 \%)$ mares. The ovulation pattern, pregnancy rate, and incidence and outcome of twin embryos in the multiple ovulators from these experiments have been reported elsewhere (Ginther \& Bergfelt, 1988; Ginther, 1989); there appeared to be no differences between naturally occurring and induced multiple ovulators.

The high multiple ovulation rate $(31 \%)$ in GnRH-treated mares is a consideration in twinprevention programmes and may be useful for embryo transfer purposes. Although other workers did not observe or did not look for increased multiple ovulation rate following GnRH induction, Johnson (1987) noted a significantly higher multiple ovulation rate in mares treated with a high dose (mean, 3 ovulations/mare; $\mathrm{N}=7$ ) than with a low dose (mean, 1.2; $N=6$ ); hCG was not included in the treatment regimen. The mean for the high dose was weighted by the occurrence of 6 ovulations in one mare. The multiple ovulation rate for controls was not determined. In the present experiments, $85 \%$ of the multiple ovulations were double and $15 \%$ were triple. The multiple ovulation rate increased progressively as dose increased but not significantly. The presence of a large follicle $(\geq 25 \mathrm{~mm})$ at start of treatment resulted in a higher multiple ovulation rate $(64 \%)$ than when the follicle was smaller $(25 \%)$. Further studies of the effect of this GnRH analogue on multiple ovulation during the ovulatory season and the role of hCG are indicated.

Research supported by College of Agricultural and Life Sciences, University of WisconsinMadison and Equiculture, Inc., Cross Plains, Wisconsin. We thank Lisa Kulick for computer and graphic assistance and Maria Westphal for preparation of the paper.

\section{References}

Allen, W.R., Sanderson, M.W., Greenwood, R.E.S., Ellis, D.R., Crowhurst, J.S., Simpson, D.J. \& Rossdale, P.D. (1987) Induction of ovulation in anoestrous mares with a slow-release implant of a $\mathrm{GnRH}$ analogue (ICI 118 630). J. Reprod. Fert., Suppl. 35, $469-478$

Evans, M.J. \& Irvine, C.H.G. (1976) Measurement of equine follicle stimulating hormone and luteinizing hormone: response of anestrous mares to gonadotropin releasing hormone. Biol. Reprod. 15, 477-484.

Evans, M.J. \& Irvine, C.H.G. (1977) Induction of follicular development, maturation and ovulation by gonadotropin releasing hormone administration to acyclic mares. Biol. Reprod. 16, 452-462.

Evans, M.J. \& Irvine, C.H.G. (1979) Induction of follicular development and ovulation in seasonally acyclic mares using gonadotrophin-releasing hormones and progesterone. J. Reprod. Fert., Suppl. 27, 113-121.

Fitzgerald, B.P., Affleck, K.J., Pemstein, R. \& Loy, R.G. (1987) Investigation of the potential of LHRH or an agonist to induce ovulation in seasonally anoestrous mares with observations on the use of the agonist in problem acyclic mares. J. Reprod. Fert., Suppl. 35, 683-684.

Garcia, M.C. \& Ginther, O.J. (1975) Plasma luteinizing hormone concentration in mares treated with gonadotropin-releasing hormone and estradiol. $\mathrm{Am}$. $J$ vet. Res. 36, 1581-1584.

Ginther, O.J. (1979) Reproductive Biology of the Mare: Basic and Applied Aspects. Equiservices, Cross Plains, Wisconsin, 417 pp.

Ginther, O.J. (1986) Ultrasonic Imaging and Reproductive Events in the Mare. Equiservices, Cross Plains, Wisconsin, 378 pp.

Ginther, O.J. (1989) The nature of embryo reduction in mares with twin conceptuses: deprivation hypothesis. Am. J. vet. Res. 50, 45-53.

Ginther, O.J. \& Bergfelt, D.R. (1988) Embryo reduction before day 11 in mares with twin conceptuses. $J$. Anim. Sci. 66, 1727-1731. 
Ginther, O.J. \& Wentworth, B.C. (1974) Effect of synthetic gonadotropin-releasing hormone on plasma concentrations of luteinizing hormone in ponies. Am. J. vet. Res. 35, 79-81.

Hyland, J.H., Wright, P.J., Clarke, I.J., Larson, R.S., Langford, D.A. \& Jeficott, L.B. (1987) Infusion of gonadotrophin-releasing hormone ( $\mathrm{GnRH}$ ) induces ovulation and fertile oestrus in mares during seasonal anoestrus. J. Reprod. Fert., Suppl. 35, 211-220.

Johnson, A.L. (1986) Induction of ovulation in anestrous mares with pulsatile administration of gonadropinreleasing hormone. Am. J. vet. Res. 47, 983-986.
Johnson, A.L. (1987) Gonadotropin-releasing hormone treatment induces follicular growth and ovulation in seasonally anestrous mares. Biol. Reprod. 36, 1199-1206.

Palmer, E. \& Quellier, P. (1988) Uses of LHRH and analogues in the mare. Proc. 1lth Int. Congr. Anim. Reprod. \& A.I., Dublin 5, 339-346.

Sharp, D.C. (1988) Transition into the breeding season: clues to the mechanisms of seasonality. Equine vet. $J$. 20, 159-161.

Received 9 March 1989 